\title{
Hypertonic saline reduces cumulative and daily intracranial pressure burdens after severe traumatic brain injury
}

\author{
Halinder S. Mangat, MD, ${ }^{1,2,5}$ Ya-Lin Chiu, MS, ${ }^{3}$ Linda M. Gerber, PhD, ${ }^{3,4}$ Marjan Alimi, MD, ${ }^{2,5}$ \\ Jamshid Ghajar, MD, PhD, ${ }^{2,6}$ and Roger Härtl, MD2,5
}

Departments of ${ }^{1}$ Neurology and ${ }^{2}$ Neurological Surgery, Weill Cornell Brain and Spine Center, and Departments of ${ }^{3}$ Public Health and ${ }^{4}$ Medicine, Weill Cornell Medical College; ${ }^{5}$ New York-Presbyterian Hospital; and ${ }^{6}$ The Brain Trauma Foundation, New York, New York

OBJECT Increased intracranial pressure (ICP) in patients with traumatic brain injury (TBI) is associated with a higher mortality rate and poor outcome. Mannitol and hypertonic saline (HTS) have both been used to treat high ICP, but it is unclear which one is more effective. Here, the authors compare the effect of mannitol versus HTS on lowering the cumulative and daily ICP burdens after severe TBI.

METHODS The Brain Trauma Foundation TBI-trac New York State database was used for this retrospective study. Patients with severe TBI and intracranial hypertension who received only 1 type of hyperosmotic agent, mannitol or HTS, were included. Patients in the 2 groups were individually matched for Glasgow Coma Scale score (GCS), pupillary reactivity, craniotomy, occurrence of hypotension on Day 1, and the day of ICP monitor insertion. Patients with missing or erroneous data were excluded. Cumulative and daily ICP burdens were used as primary outcome measures. The cumulative ICP burden was defined as the total number of days with an ICP of $>25 \mathrm{~mm} \mathrm{Hg}$, expressed as a percentage of the total number of days of ICP monitoring. The daily ICP burden was calculated as the mean daily duration of an ICP of $>25 \mathrm{~mm} \mathrm{Hg}$, expressed as the number of hours per day. The numbers of intensive care unit (ICU) days, numbers of days with ICP monitoring, and 2-week mortality rates were also compared between the groups. A 2-sample t-test or chisquare test was used to compare independent samples. The Wilcoxon signed-rank or Cochran-Mantel-Haenszel test was used for comparing matched samples.

RESULTS A total of 35 patients who received only HTS and 477 who received only mannitol after severe TBI were identified. Eight patients in the HTS group were excluded because of erroneous or missing data, and 2 other patients did not have matches in the mannitol group. The remaining 25 patients were matched 1:1. Twenty-four patients received $3 \%$ HTS, and 1 received $23.4 \%$ HTS as bolus therapy. All 25 patients in the mannitol group received $20 \%$ mannitol. The mean cumulative ICP burden (15.52\% [HTS] vs 36.5\% [mannitol]; $p=0.003)$ and the mean $( \pm$ SD) daily ICP burden $(0.3$ \pm 0.6 hours/day [HTS] vs $1.3 \pm 1.3$ hours/day [mannitol]; $p=0.001$ ) were significantly lower in the HTS group. The mean $( \pm S D)$ number of ICU days was significantly lower in the HTS group than in the mannitol group (8.5 \pm 2.1 vs 9.8 \pm 0.6 , respectively; $p=0.004)$, whereas there was no difference in the numbers of days of ICP monitoring $(p=0.09)$. There were no significant differences between the cumulative median doses of HTS and mannitol $(p=0.19)$. The 2-week mortality rate was lower in the HTS group, but the difference was not statistically significant $(p=0.56)$.

CONCLUSIONS HTS given as bolus therapy was more effective than mannitol in lowering the cumulative and daily ICP burdens after severe TBI. Patients in the HTS group had significantly lower number of ICU days. The 2-week mortality rates were not statistically different between the 2 groups.

http://thejns.org/doi/abs/10.3171/2014.10.JNS132545

KEY WORDS traumatic brain injury; hypertonic saline; mannitol; intracranial pressure; ICP burden

ABBREVIATIONS AUC = area under the curve; CBF = cerebral blood flow; CMH = Cochran-Mantel-Haenszel; CPP = cerebral perfusion pressure; GCS = Glasgow Coma Scale; BTF = Brain Trauma Foundation; HTS = hypertonic saline; ICP = intracranial pressure; ICU = intensive care unit; RCT = randomized controlled trial; TBI = traumatic brain injury.

SUBMITTED November 15, 2013. ACCEPTED October 2, 2014.

INCLUDE WHEN CITING Published online November 7, 2014; DOI: 10.3171/2014.10.JNS132545.

DISCLOSURE Dr. Härtl reports being a consultant for DePuy-Synthes, Lanx, AOSpine, and Brainlab. Dr. Ghajar is president of the Brain Trauma Foundation. 
$\mathrm{T}$ RAUMATIC brain injury (TBI) remains a significant cause of death and disability. Guidelines for the management of severe TBI (hereafter referred to as guidelines) have been published by the Brain Trauma Foundation (BTF), and adherence to these guidelines has been associated with a significant reduction in the mortality rate. ${ }^{3,15}$ The guidelines include a Level II recommendation for the use of mannitol for the treatment of high intracranial pressure (ICP) and state that "mannitol is effective in reducing ICP in the management of traumatic intracranial hypertension" and that "current evidence is not strong enough to make recommendations on the use, concentration and method of administration of hypertonic saline for the treatment of traumatic intracranial hypertension."4

Intracranial hypertension and cerebral hypoperfusion are common occurrences after severe TBI and are associated with worse outcome, whereas a response to ICPlowering treatment is associated with a decreased mortality rate..$^{10,11,29,35}$ Mannitol reduces ICP and mortality rates after head injury and is superior to pentobarbital in reducing the occurrence and severity of ICP elevations. ${ }^{30,45,47}$ However, hypertonic saline (HTS) has increasing pilot data supporting its efficacy. ${ }^{1,17,20,21,25,48,51}$ Recent meta-analyses of observational studies comparing mannitol and HTS in the treatment of raised ICP support HTS as a superior agent for lowering ICP. ${ }^{24,32}$ One of the meta-analyses included 5 trials (not restricted to TBI) with a total of 112 patients and found that HTS was overall superior in controlling ICP elevations, with a higher odds ratio favoring ICP control, and a greater reduction in the occurrence and severity of ICP. ${ }^{24}$

Several published studies favoring HTS were small and included pooled data from patients with different causes of brain injury (TBI, stroke, subarachnoid hemorrhage). These data do not provide adequate evidence for specific brain injury diagnoses but rather yield a broad basis for additional study. In addition, all studies published to date examined the effects of mannitol or HTS only on discrete episodes of intracranial hypertension, and the rapidity and duration of reduction of ICP spikes, and no data exist on the efficacy of either agent in reducing the cumulative ICP burden. Therefore, using prospectively collected data, we undertook this study to compare the effects of mannitol and HTS on the cumulative and daily ICP burdens, rather than on single episodes of intracranial hypertension, in patients with severe TBI.

\section{Methods}

\section{TBI-trac Database}

As part of a quality improvement program, the BTF developed the TBI-trac database to track compliance with the guidelines for the management of severe TBI and to test clinical hypotheses that could improve the existing BTF guidelines. Trained nurse coordinators at participating hospitals were required to collect and enter clinical information about patients with severe TBI into the database in a prospective manner. The clinical information included data from the prehospitalization period, the emergency department, and the first 10 days in the intensive care unit (ICU), as well as 2-week mortality data. Use of the database and the quality improvement program was funded by the New York State Department of Health and was deployed across 22 trauma centers in New York State. The research protocol was approved by or exempt from review by the institutional review boards of all the participating institutions. For patient confidentiality, no identifiers were entered into the database.

\section{Study Population}

We reviewed data on patients admitted between June 6, 2000, and August 21, 2008, and included patients aged 16 years or older who had suffered a severe TBI and were hospitalized for at least 5 days. In addition, patients were included if they received only 1 hyperosmotic agent, mannitol or HTS, for the treatment of intracranial hypertension. For patients who received both mannitol and HTS, data were not available on whether use of the second agent was specifically for treatment failure or for other reasons such as drug availability or physician choice. Therefore, to prevent erroneous conclusions, patients who received both agents were not included for data analysis. Patients were excluded if they met one of the following criteria on Day 1: Glasgow Coma Scale (GCS) score of $>9$, motor score of 6, GCS score of 3 with bilateral fixed and dilated pupils, death on Day 1, or arrival at the trauma center 24 hours or more after injury. Patients with advanced directives requesting no heroic measures or a do-not-resuscitate/donot-intubate instruction were also excluded.

\section{Outcome Variables}

The primary outcomes were cumulative ICP burden (\%) and daily ICP burden (hours/day). The cumulative ICP burden was calculated as the sum of the number of days a patient had an ICP spike (ICP > $25 \mathrm{~mm} \mathrm{Hg}$ ) as a percentage of the total number of days of ICP monitoring. An average daily burden of elevated ICP (ICP $>25 \mathrm{~mm} \mathrm{Hg}$ ) was also calculated (hours/day). Furthermore, we examined total number of ICU days, number of days of ICP monitoring, and the 2-week mortality rate. In addition, we evaluated the total ICP burden during the first half of ICP monitoring period and compared it to that during the second half for both groups, and we performed in-group and between-group comparisons. In the database, HTS doses were specified by concentration and volume administered, and mannitol doses were specified as escalating dose ranges in grams. Therefore, we used the recorded dose for HTS and median dose of ranges for mannitol to calculate the cumulative dose. We then converted these doses to equiosmolar dose ranges for HTS on the basis of the dose ranges specified for mannitol in the database (Table 1).

\section{Statistical Analyses}

The goal of the study was to compare the effect of mannitol and HTS on the outcome variables described above. Descriptive summaries of the data are presented as mean $\pm \mathrm{SD}$ or median (interquartile range) for continuous variables and frequencies for categorical variables. Differences in the baseline variables between the 2 groups were assessed using 2 methods. First, the 2-sample t-test was used for continuous variables, and the chi-square or Fisher exact test was used for categorical variables. 
TABLE 1. Equiosmolar dose-range calculation for mannitol and HTS

\begin{tabular}{cccc}
\hline $\begin{array}{c}\text { Mannitol Dose } \\
(\mathrm{g})\end{array}$ & $\begin{array}{c}3 \% \text { HTS Dose } \\
(\mathrm{ml})\end{array}$ & $\begin{array}{c}23.4 \% \text { HTS } \\
\text { Dose }(\mathrm{ml})\end{array}$ & $\begin{array}{c}\text { Osmolality } \\
(\mathrm{mOsm})\end{array}$ \\
\hline $0-50$ & $0-268$ & $0-34$ & $0-275$ \\
\hline $51-100$ & $269-536$ & $35-68$ & $276-550$ \\
\hline $101-200$ & $537-1072$ & $69-136$ & $551-1100$ \\
\hline $201-600$ & $1073-3216$ & $137-408$ & $1101-3300$ \\
\hline
\end{tabular}

Second, the standardized difference was computed for each baseline variable. The standardized difference was defined as the difference in mean in units of the pooled standard deviation for assessing the imbalance in covariates between patients in the 2 groups..$^{12}$ It has been suggested that a standardized difference of $>20 \%$ represents meaningful imbalances between groups. ${ }^{6}$ We used either a $p$ value of $<0.05$ or a standardized difference of $>20 \%$ for determining baseline differences between the groups.

\section{Patient Matching}

Age, initial GCS score, hypotension, pupil reactivity, CT scan abnormalities, and surgical lesions have been shown to predict 2 -week mortality rates after severe TBI. ${ }^{10}$ We therefore attempted to match patients in the 2 groups for these factors and day of ICP monitor insertion. Because of the small number of patients in the HTS group $(n=35)$, a regular propensity score generated from a multivariate logistic regression model was not feasible. We therefore used an exact matching approach to control for baseline differences between the groups. ${ }^{42}$ To have maximum numbers of matching pairs, age and baseline CT abnormalities were not included in the matching because their standardized difference was $<20 \%$, and the $p$ value was $>0.05$ (i.e., balanced between the 2 groups). We evaluated the balance of these baseline variables between the groups after matching. In addition to the 1:1 matching, we also performed a 1:2 matching for sensitivity analysis. Patients in the HTS group with no match in the mannitol group, or with missing or erroneous data, were excluded.

The Wilcoxon signed-rank test was used for matched samples, and the Cochran-Mantel-Haenszel (CMH) test was used for continuous variables. Corresponding overall common odds ratios and $95 \%$ confidence intervals were calculated for categorical variables for comparisons between groups. In the 1:2 matching samples, the average of continuous variables from the 2 matching patients who were given mannitol was calculated before statistical testing was conducted. All statistical tests were 2 -sided, and a p value of $<0.05$ was considered statistically significant. Analyses were performed using SAS version 9.2 software (SAS Institute Inc.).

\section{Results}

\section{Patient Selection and Matching}

A total of 2641 patients with TBI from 22 trauma centers were identified in the database, and 1327 met all the inclusion criteria. Of these patients, 589 received no hyperosmotic agent, 137 received both HTS and mannitol, and 512 received either HTS or mannitol alone for the management of intracranial hypertension; 89 patients had missing data on the administration of hyperosmotic therapy. Baseline characteristics of all the patients are shown in Table 2.

We identified 35 patients who received HTS only and 477 who received mannitol only. Eight patients were excluded in the HTS group; 7 had missing ICP data, and 1 had wrong HTS dose information. Therefore, 27 patients from the HTS group were included for the exact matching approach. Of the 27 patients, 25 had an exact match with 25 patients in the mannitol group and were included for additional data analyses (Fig. 1). All patients in the mannitol group received $20 \%$ mannitol. Twenty-four patients in the HTS group received a $3 \%$ and 1 patient received a $23.4 \%$ bolus of HTS (the osmolar doses were similar for 3\% and 23.4\% HTS) (Table 1). With 1:2 matching, 24 patients in the HTS group had 48 corresponding matched patients in the mannitol group.

A comparison of the baseline characteristics of the unpaired patients in the 2 study groups is shown in Table 3 . When the criteria described above were applied, there was an imbalance of baseline characteristics in the matching variables of the 2 cohorts (standardized difference $>$ $20 \%$ or $\mathrm{p}<0.05)$. However, in the matched (1:1) group, the baseline data were comparable (Table 4). In each group, $6(17.1 \%)$ of 35 patients had a pupillary abnormality, 8 (23.5\%) had hypotension, and 7 (20.6\%) underwent craniotomy. ICP monitors were placed, on average, by the 2nd day (mean $1.16 \pm 0.47$ ) after admission to the ICU, and the mean GCS score in both groups was $5.4 \pm 1.55$. Age was balanced between the 2 groups (mean $34.96 \pm$ 15.41 years [HTS] vs $36.68 \pm 16.90$ years [mannitol]; $p$ $=0.96)$. Although the standardized difference increased to $17 \%$ for CT scan abnormalities, it was a result of the small sample size. The proportions of patients with CT scan abnormalities were comparable ( $92 \%$ in the HTS group vs $96 \%$ in the mannitol group; $\mathrm{p}=0.56$ ). Overall, the matched baseline data were balanced between the 2 groups.

\section{Intracranial Pressure Reduction}

The results from the 1:1 pairing are shown in Table 5 . The total numbers of days of ICP recording in the 2 groups was not significantly different $(6.4 \pm 2.7$ days [HTS] vs $7.7 \pm$ 2.7 days [mannitol]; $p=0.09$ ). The cumulative ICP burden was significantly lower in patients who received HTS than in those who received mannitol $(15.2 \% \pm 19.9 \%$ vs $36.5 \%$ $\pm 30.9 \%$, respectively; $p=0.003$ ). The daily ICP burden was also significantly lower in the HTS group than in the mannitol group $(0.3 \pm 0.6$ hours/day vs $1.3 \pm 1.3$ hours/ day, respectively; $p=0.001$ ). Results from the $1: 2$ matched comparisons are shown in Table 5. The cumulative ICP and daily ICP burdens remained significantly lower for the HTS group. The cumulative median dose ranges of HTS and mannitol were comparable (median 1101-3300 mOsm vs $551-1100 \mathrm{mOsm}$, respectively; $\mathrm{p}=0.19$ ).

To evaluate whether the effectiveness of HTS or mannitol changed with repeated dosing, we compared the total ICP burdens (hours) between the first and second halves of the ICP monitoring period and found no difference in 
TABLE 2. Baseline characteristics of the groups

\begin{tabular}{lcccc}
\hline \multicolumn{1}{c}{ Characteristic } & $\begin{array}{c}\text { Neither HTS nor } \\
\text { Mannitol }\end{array}$ & HTS Only & Mannitol Only & Both HTS \& Mannitol \\
\hline No. of patients & 589 & 35 & 477 & 137 \\
\hline Mean age (yrs) & $42.63 \pm 20.23$ & $38.37 \pm 19.02$ & $36.13 \pm 17.03$ & $31.42 \pm 15.11$ \\
\hline Mean GCS score & $4.96 \pm 1.76$ & $5.46 \pm 1.63$ & $4.75 \pm 1.80$ & $4.82 \pm 1.71$ \\
\hline Abnormal pupils (no. [\%]) & $99(17.0)$ & $6(17.1)$ & $125(26.7)$ & $36(26.7)$ \\
\hline Hypotension (no. [\%]) & $89(15.2)$ & $8(22.9)$ & $63(13.3)$ & $15(11.0)$ \\
\hline Craniotomy (no. [\%]) & $126(21.4)$ & $7(20.0)$ & $208(43.6)$ & $67(48.9)$ \\
\hline Mean day of ICP monitor insertion & $0.98 \pm 1.03$ & $1.03 \pm 0.92$ & $1.34 \pm 1.16$ & $1.13 \pm 0.38$ \\
\hline CT scan abnormalities (no. [\%]) & $439(78.7)$ & $32(91.4)$ & $409(89.9)$ & $124(91.2)$ \\
\hline
\end{tabular}

either group (Table 6). Furthermore, there was no intergroup difference in the change in total ICP burden from the first half to the second half. The total ICP burden was significantly lower in the HTS group in both halves of ICP monitoring period.

\section{Length of ICU Stay and Mortality Rate}

The duration of the ICU stay was significantly lower in the HTS group in the 1:1 matched comparison $(8.5 \pm 2.1$ days [HTS] vs $9.8 \pm 0.6$ days [mannitol]; $\mathrm{p}=0.004$ ), and it approached a marginal difference in the 1:2 matched groups $(8.6 \pm 2.1$ days [HTS] vs $9.4 \pm 1.1$ days [mannitol]; $\mathrm{p}=0.06$ ). The 2 -week mortality rate was lower in the HTS group in both matched group comparisons, but this was not statistically significant $(1: 1$ match common OR 0.50
[95\% CI 0.05-5.51] [p = 0.56]; 1:2 match common OR 0.50 [95\% CI $0.06-4.47][\mathrm{p}=0.53])$.

\section{Discussion}

In this study, we examined the effect of mannitol and HTS on raised ICP over the entire course of treatment for intracranial hypertension after severe TBI. Our findings illustrate that HTS is superior to mannitol in reducing cumulative and daily ICP burdens after severe TBI. Our results are strengthened by matching patients in both groups for variables known to affect early death after TBI. ${ }^{10}$ In addition, the total number of ICU days was significantly lower in the HTS group, but the mortality rates were not significantly different, although there was a tendency for a lower mortality rate in the HTS group.

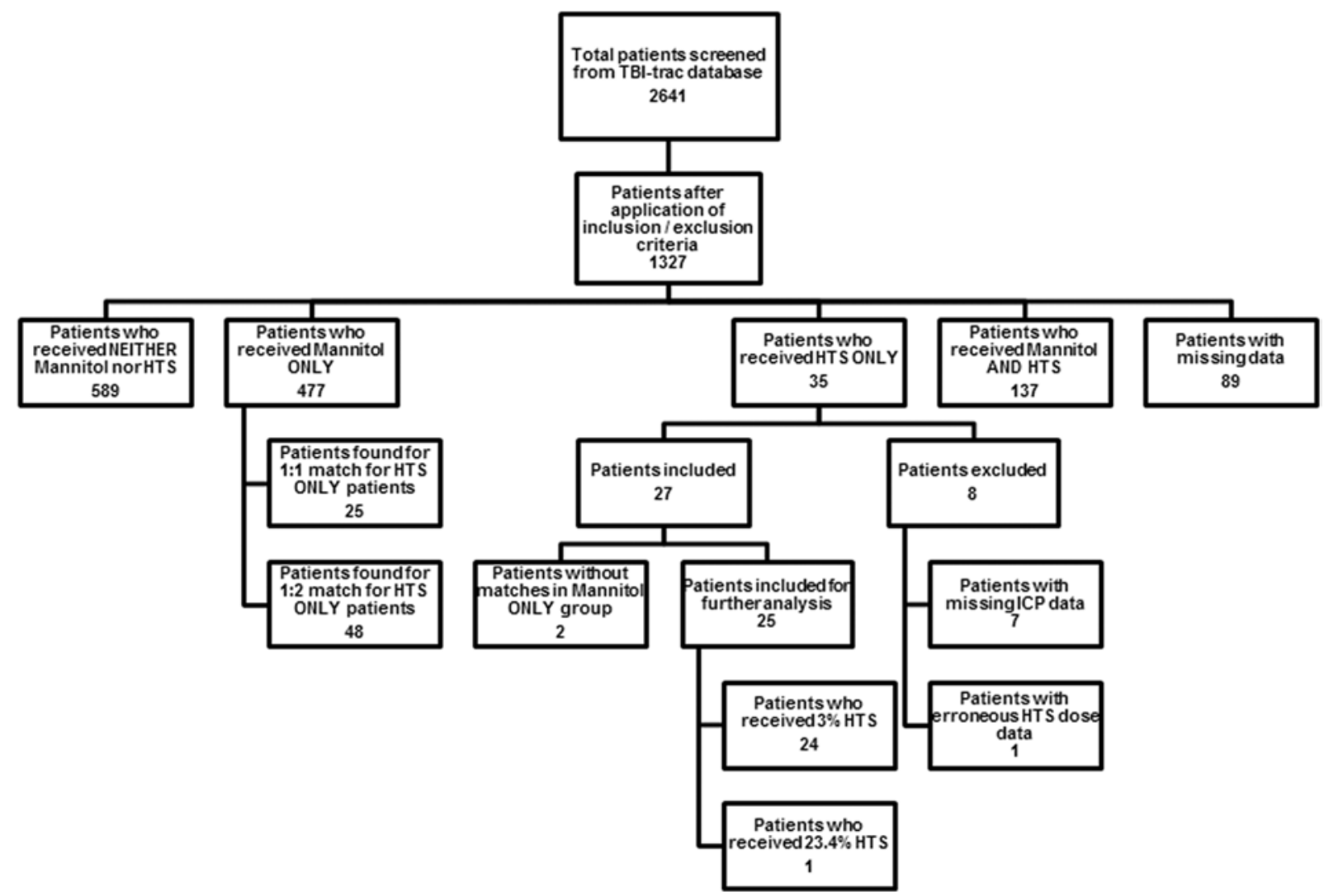

FIG. 1. Flow chart showing the selection of patients for study. 
TABLE 3. Comparison of baseline characteristics of the 2 study groups before matching

\begin{tabular}{lcccc}
\hline \multicolumn{1}{c}{ Characteristic } & HTS Only & Mannitol Only & $\begin{array}{c}\text { Standardized } \\
\text { Difference (\%) }\end{array}$ & p Value \\
\hline No. of patients & 35 & 477 & & 0.46 \\
\hline Mean age (yrs) & $38.37 \pm 19.02$ & $36.13 \pm 17.03$ & 12.4 & 0.02 \\
\hline Mean GCS score & $5.46 \pm 1.63$ & $4.75 \pm 1.80$ & 41.1 & 0.21 \\
\hline Abnormal pupils (no. [\%]) & $6(17.1)$ & $125(26.7)$ & 23.3 & 0.13 \\
\hline Hypotension (no. [\%]) & $8(22.9)$ & $63(13.3)$ & 25.1 & 0.01 \\
\hline Craniotomy (no. [\%]) & $7(20.0)$ & $208(43.6)$ & 52.4 & 0.12 \\
\hline Mean day of ICP monitor insertion & $1.03 \pm 0.92$ & $1.34 \pm 1.16$ & 29.7 & $>0.99$ \\
\hline CT scan abnormalities (no. [\%]) & $32(91.4)$ & $409(89.9)$ & 5.3 & \\
\hline$*$ The p values were calculated using the 2-sample t-test or chi-square test. & & &
\end{tabular}

\section{Hypertonic Saline Versus Mannitol}

Hypertonic saline and mannitol share similar mechanisms in reducing raised ICP. Both of them work by establishing an osmotic gradient across the blood-brain barrier, leading to fluid shifts from the intercellular space into the microcirculation. ${ }^{2,36,54}$ The immediate reduction in ICP is likely related to an increase in cardiac output and improvement in laminar blood flow in capillaries by the effects on red blood cell rheology, dehydration of endothelial cells, and decreased blood viscosity. $5,8,34,53$ This process takes several minutes and lasts up to a few hours. ${ }^{36}$ HTS and mannitol also have antiinflammatory effects. ${ }^{19,28}$

Clinically, HTS and mannitol have each been shown, in several observational and nonrandomized studies, to reduce ICP and improve brain physiology to different extents. In an initial prospective study, Härtl et al. showed that $7.5 \%$ HTS reduced ICP and increased cerebral perfusion pressure (CPP) in patients with TBI. ${ }^{17}$ Several other studies also demonstrated that HTS reduces ICP when it is used as a first-line agent or in patients with intracranial hypertension refractory to mannitol, and it increases CPP and brain oxygenation. ${ }^{20,37,40,44}$ Hypertonic saline has a more pronounced and longer-lasting effect on raised ICP than mannitol and does not cause a rebound increase in ICP. ${ }^{17,25,51}$ It causes quick and sustained volume expansion and is effective in lowering raised ICP refractory to other therapies. ${ }^{7,9,17,18,25,51}$ Single doses of $23.4 \%$ HTS can reverse transtentorial herniation and improve cerebral blood flow $(\mathrm{CBF}), \mathrm{CPP}$, and cerebral oxygenation. ${ }^{27,37,40}$ Although mannitol also increases CPP and CBF and reduces ICP, the increases in CPP and CBF are smaller than those seen with HTS and are not associated with an increase in cerebral oxygenation. . $^{16,31,33,37}$

There have been no large randomized controlled trials (RCTs) comparing HTS and mannitol in severe TBI. A few small RCTs using equimolar and/or isovolumic dose comparisons provide limited data from heterogeneous groups of patients. ${ }^{1,7,13,21,48}$ A comparison of isovolumic doses of $7.5 \%$ HTS and $20 \%$ mannitol demonstrated that HTS provided greater reductions in the number and duration of ICP spikes than those with mannitol. ${ }^{48}$ In 3 studies using equimolar doses of HTS and mannitol, HTS demonstrated either equal or greater reductions in ICP and longer durations of effect, and mannitol produced significantly greater diuresis and volume loss. ${ }^{1,7,13}$ In a comparison of equimolar and isovolumic doses of hypertonic sodium lactate and mannitol in patients with TBI, hypertonic sodium lactate produced a greater magnitude and duration of ICP lowering and a higher CPP than did mannitol. ${ }^{21}$

In some of the randomized trials discussed above, patients with TBI with cerebrospinal fluid diversion and surgical lesions were excluded, whereas patients with strokes were included in others. ${ }^{1,13,21}$ This limits the application of these data to a large proportion of patients with severe TBI because cerebrospinal fluid diversion and surgical evacuation of intracranial lesions are common. The inclusion of patients who have had a stroke makes it difficult to make inferences because of different pathophysiological mechanisms and natural history. Furthermore, the subgroups of patients with TBI received both HTS and mannitol ac-

TABLE 4. Baseline characteristics of the 2 study groups after matching

\begin{tabular}{|c|c|c|c|c|}
\hline Characteristic & HTS & Mannitol & $\begin{array}{l}\text { Standardized } \\
\text { Difference (\%) }\end{array}$ & p Value* \\
\hline No. of patients & 25 & 25 & & \\
\hline Age in yrs (mean \pm SD) & $34.96 \pm 15.41$ & $36.68 \pm 16.90$ & 10.1 & 0.96 \\
\hline GCS score (mean \pm SD) & \multicolumn{2}{|c|}{$5.40 \pm 1.55$} & & \\
\hline Abnormal pupils (no. [\%]) & \multicolumn{2}{|c|}{$4(16.0)$} & & \\
\hline Hypotension (no. [\%]) & \multicolumn{2}{|c|}{$4(16.0)$} & & \\
\hline Craniotomy (no. [\%]) & \multicolumn{2}{|c|}{$6(24.0)$} & & \\
\hline Day of ICP monitor insertion (mean \pm SD) & \multicolumn{2}{|c|}{$1.16 \pm 0.47$} & & \\
\hline CT scan abnormalities (no. [\%]) & $23(92.0)$ & $24(96.0)$ & 16.9 & 0.56 \\
\hline
\end{tabular}

* The $p$ values were calculated using the Wilcoxon signed-rank or $\mathrm{CMH}$ test for paired data. 
TABLE 5: Study outcomes in the 2 groups with matching

\begin{tabular}{cccc}
\hline Characteristic & HTS & Mannitol & p Value* \\
\hline 1:1 matching (no.) & 25 & 25 & 0.09 \\
\hline Mean no. of days w/ ICP recorded & $6.4 \pm 2.7$ & $7.7 \pm 2.7$ & $0.004 \ddagger$ \\
\hline Mean no. of days in ICU & $8.5 \pm 2.1$ & $9.8 \pm 0.6$ & $0.003 \ddagger$ \\
\hline Mean cumulative ICP burden (\%)† & $15.2 \pm 19.9$ & $36.5 \pm 30.9$ & $0.001 \ddagger$ \\
\hline Mean daily ICP burden (hrs/day) & $0.3 \pm 0.6$ & $1.3 \pm 1.3$ & 0.19 \\
\hline Cumulative median dose (mOsm), IQR & $1101-3300$ & $551-1100$ & 0.56 \\
\hline 2-wk deaths (no. [\%]) & $1(4)$ & $2(8)$ & 0.46 \\
\hline 1:2 matching (sensitivity analysis) (no.) & 24 & 48 & 0.06 \\
\hline Mean no. of days w/ ICP recorded & $6.6 \pm 2.6$ & $7.1 \pm 2.0$ & $0.001 \ddagger$ \\
\hline Mean no. of days in ICU & $8.6 \pm 2.1$ & $9.4 \pm 1.1$ & $<0.0001 \ddagger$ \\
\hline Mean cumulative ICP burden (\%) $\dagger$ & $15.8 \pm 20.1$ & $39.3 \pm 23.3$ & 0.35 \\
\hline Mean daily ICP burden (hrs/day) & $0.3 \pm 0.6$ & $1.8 \pm 2.1$ & 0.53 \\
\hline Cumulative median dose (mOsm), IQR & $550-1100$ & $275-550$ & $4(8.3)$ \\
\hline 2-wk deaths (no. [\%]) & $1(4.2)$ & & \\
\hline
\end{tabular}

* The Wilcoxon signed-rank test was used to test the median difference between groups resulting from a small sample size, and the $\mathrm{CMH}$ test was used for 2-week mortalities.

$\dagger$ ICP burden is defined as the percentage of the number of days with an ICP of $>25 \mathrm{~mm} \mathrm{Hg} / \mathrm{number}$ of days ICP was monitored.

$\ddagger$ Significant difference.

cording to study designs and were not matched for factors known to affect short-term outcome. In contrast, our study included only patients with severe TBI and provides data from the largest number of patients studied to compare the efficacy of HTS and mannitol in ICP reduction. All the patients in our study received only 1 hyperosmotic agent and were matched for GCS score, pupillary reactivity, craniotomy, and occurrence of hypotension on Day 1, which all affect short-term outcome after TBI, and patients with surgical lesions were included. A 1:2 patient matching between HTS and mannitol further strengthens our observations.

\section{Cumulative ICP Reduction}

Most studies have examined the effect of osmotic agents on single ICP elevations. In our study, we examined the cumulative ICP burden rather than the effect on individual ICP spikes imposed by repeated elevations of ICP. In patients with severe TBI and high ICP, the area under the curve (AUC) for ICP has been shown to be a significant predictor of poor outcome at 6 months and of death, and the AUC was significantly higher in patients with a higher Marshall score. ${ }^{49}$ Sheth et al. used automated "pressure times time dose" (PTD) to demonstrate that the total PTD for patients with an ICP of $>20 \mathrm{~mm} \mathrm{Hg}$ and CPP of $<60$ $\mathrm{mm} \mathrm{Hg}$ had a high predictive power for functional outcome and in-hospital mortality. ${ }^{23,46}$ These methods were also validated in a study in the pediatric population, in which the ICP AUC was correlated with mortality, and the cumulative pressure-time index for below-threshold CPP was correlated with outcome morbidity and mortality. ${ }^{22,50}$ Therefore, the measurement of daily and cumulative ICP burdens is a meaningful outcome variable.

\section{Length of ICU Stay and Mortality Rate}

This study also provides data on the benefit of HTS on length of ICU stay. Patients who received HTS spent fewer days in the ICU than patients who received mannitol. In comparison, adherence to mannitol use per Austrian guidelines has been shown to reduce length of hospitalization but not duration of ICU stay. ${ }^{43} \mathrm{~A}$ larger cohort is required to perform the additional cost-benefit analysis, but a shorter ICU stay coupled with decreased dosing of HTS and other ICU interventions would result in significant cost savings. There was a tendency for lower 2-week

TABLE 6: Comparisons of total ICP burdens in the first versus the second half of ICP monitoring duration in the 2 groups

\begin{tabular}{|c|c|c|c|c|}
\hline \multirow[b]{3}{*}{ Factor } & \multicolumn{4}{|c|}{ Total ICP Burden } \\
\hline & \multicolumn{2}{|c|}{ HTS } & \multicolumn{2}{|c|}{ Mannitol } \\
\hline & 1st Half of ICP Monitoring & 2nd Half of ICP Monitoring & 1st Half of ICP Monitoring & 2nd Half of ICP Monitoring \\
\hline No. of patients & 25 & 25 & 25 & 25 \\
\hline Mean hours & $1.32 \pm 2.70$ & $0.92 \pm 2.29$ & $5.96 \pm 7.68$ & $5.64 \pm 7.39$ \\
\hline$p$ value & \multicolumn{2}{|c|}{$0.67^{*}$} & \multicolumn{2}{|c|}{$0.63^{*}$} \\
\hline$p$ value & \multicolumn{4}{|c|}{$0.72 \dagger$} \\
\hline
\end{tabular}


mortality rate in the HTS group, although this tendency was not statistically significant.

\section{Osmolar Dose Comparison}

The studies cited above compared dose formulations that were isovolumic, equiosmolar, or both. 1,7,13,21,48 Hyperosmolar therapy in our patients was titrated to the effect on ICP, and osmolar or volume considerations were not used for dosing. However, we calculated the cumulative osmotic doses of HTS and mannitol and compared them in both groups. In our data, the median cumulative doses were not statistically different between the 2 groups.

Typically, the administration of different volumes of mannitol or HTS boluses does not pose a problem. HTS and mannitol have opposite effects on volume status; HTS causes volume expansion, and mannitol causes diuresis. The cerebral effects also may vary because of differences in reflectance coefficients. Therefore, equimolar doses may not have equivalent effects in ICP reduction, which is supported by our data, because HTS produced greater cumulative ICP reduction with a median cumulative dose similar to that of mannitol.

\section{Change in Efficacy}

Finally, we examined the effects of mannitol and HTS on ICP reduction during the first and second halves of the ICP monitoring period. We found no changes in the efficacy of either agent between the first and second halves of the treatment period. There were also no differences in the changes in ICP burden between the 2 halves of the ICPmonitoring period for either agent, suggesting that HTS and mannitol both retain their effectiveness with repeated dosing.

\section{Limitations of the Study \\ Study Design}

This study was a retrospective analysis of data and was not powered for the highest level of benefit analysis. However, the data were collected in a consistent, systematic, and prospective manner from several centers.

\section{Sample Size}

The total number of patients in our study was small. However, compared with the other studies discussed above, it is the largest group of patients thus far studied to compare the effects of HTS and mannitol on ICP reduction after TBI. In addition, the patients included in our study were matched for all variables that affect short-term outcome after TBI, which makes our observations more robust. In addition, the subjects selected received only 1 hyperosmotic agent throughout their treatment, and all patients except 1 in the HTS group received 3\% HTS.

Patients who received both HTS and mannitol were not included because the reasons for the administration of both agents were not available. Although the use of both agents may imply treatment failure with 1 agent, it may also merely represent physician choice or drug availability. In addition, these patients did not represent an unduly large subgroup (10.32\%).

\section{Dosing Methods: Bolus Versus Continuous Infusion}

In pediatric patients, the use of continuous HTS infusion has been shown to reduce ICP. ${ }^{26,38}$ However, although the use of continuous HTS infusion has been shown in adults to be safe, its benefit in ICP reduction has not been demonstrated.$^{14,39,41,52}$ We examined HTS therapy using bolus dosing. Therefore, the conclusions can be applied for the use of HTS bolus therapy only and not for the use of continuous HTS infusions to reduce ICP.

\section{Specific Treatments}

The study did not address specific treatments used to control ICP crises other than HTS and mannitol. However, surgical lesions were matched in the 2 groups.

\section{Factors Influencing Choice of Osmotic Agent}

We were not able to determine the reasons for the choice of HTS or mannitol. It is unknown if drug availability, physician preference, or clinical comorbidities affected the physicians' choices (e.g., heart failure favoring mannitol and renal injury favoring HTS). These comorbidities may play a role in clinical outcomes; however, both groups had generally young patients. Also, by matching patients for other variables that affect outcome, we made every effort to remove selection bias between the 2 groups.

\section{Adverse Effects}

Hypertonic saline and mannitol have been documented to cause different adverse effects. HTS can cause volume overload, cardiac failure, and renal failure when the serum sodium level is markedly elevated. Similarly, mannitol can cause renal failure as a result of precipitation in the renal tubules. No data on the adverse effects of these agents were available in the database.

\section{Conclusions}

In the absence of an RCT, there is no consensus on the superiority of either HTS or mannitol in treating intracranial hypertension after severe TBI. We examined prospectively collected data from 22 trauma centers in New York State. Patients in the study were matched for factors affecting short-term mortality rate after TBI (GCS score, pupillary abnormality, hypotension, and surgical lesions) and were comparable in age and CT scan abnormalities. Compared with mannitol, bolus HTS therapy provided significantly greater reduction in cumulative ICP burden, measured as the percentage of days of intracranial hypertension; HTS use was also associated with significantly reduced daily ICP burden and fewer ICU days. The 2-week mortality rates were not statistically different in the 2 groups. Reduction in the number of ICU days along with the less-frequent administration requirements suggest that HTS may be a preferable agent in reducing ICU costs. These results further impress on the need to conduct an RCT to compare long-term outcome benefits between mannitol and HTS treatment.

\section{Acknowledgments}

We thank the New York State Department of Health, the Brain Trauma Foundation, and the NewYork-Presbyterian Hospital 
TBI fund for their financial support. We gratefully acknowledge additional support from Clinical Translational Science Center, National Center for Advancing Translational Sciences, grant no. UL1-TR000457-06.

\section{References}

1. Battison C, Andrews PJ, Graham C, Petty T: Randomized, controlled trial on the effect of a $20 \%$ mannitol solution and a $7.5 \%$ saline $/ 6 \%$ dextran solution on increased intracranial pressure after brain injury. Crit Care Med 33:196-202, 2005

2. Berger S, Schürer L, Härtl R, Messmer K, Baethmann A: Reduction of post-traumatic intracranial hypertension by hypertonic/hyperoncotic saline/dextran and hypertonic mannitol. Neurosurgery 37:98-108, 1995

3. Brain Trauma Foundation, American Association of Neurological Surgeons, Congress of Neurological Surgeons, AANS/CNS Joint Section on Neurotrauma and Critical Care: Guidelines for the management of severe traumatic brain injury, ed 3. J Neurotrauma 24 (Suppl 1):S1-S106, 2007 (Erratum in J Neurotrauma 25:276-278, 2008)

4. Bratton SL, Chestnut RM, Ghajar J, McConnell Hammond FF, Harris OA, Hartl R, et al: Guidelines for the management of severe traumatic brain injury. II. Hyperosmolar therapy. J Neurotrauma 24 (Suppl 1):S14-S20, 2007 (Erratum in J Neurotrauma 25:276-278, 2008)

5. Burke AM, Quest DO, Chien S, Cerri C: The effects of mannitol on blood viscosity. J Neurosurg 55:550-553, 1981

6. Cohen J: Statistical Power Analysis for the Behavioral Sciences, ed 2. Hillsdale, NJ: L Erlbaum Associates, 1988

7. Cottenceau V, Masson F, Mahamid E, Petit L, Shik V, Sztark F, et al: Comparison of effects of equiosmolar doses of mannitol and hypertonic saline on cerebral blood flow and metabolism in traumatic brain injury. $\mathbf{J}$ Neurotrauma 28:2003-2012, 2011

8. Doyle JA, Davis DP, Hoyt DB: The use of hypertonic saline in the treatment of traumatic brain injury. J Trauma 50:367383, 2001

9. Eskandari R, Filtz MR, Davis GE, Hoesch RE: Effective treatment of refractory intracranial hypertension after traumatic brain injury with repeated boluses of $14.6 \%$ hypertonic saline. Clinical article. J Neurosurg 119:338-346, 2013

10. Farahvar A, Gerber LM, Chiu YL, Carney N, Härtl R, Ghajar $\mathrm{J}$ : Increased mortality in patients with severe traumatic brain injury treated without intracranial pressure monitoring. Clinical article. J Neurosurg 117:729-734, 2012

11. Farahvar A, Gerber LM, Chiu YL, Härtl R, Froelich M, Carney N, et al: Response to intracranial hypertension treatment as a predictor of death in patients with severe traumatic brain injury. Clinical article. J Neurosurg 114:1471-1478, 2011 (Erratum in J Neurosurg 115:191, 2011)

12. Flury BK, Riedwyl H: Standard distance in univariate and multivariate analysis. Am Stat 40:249-251, 1986

13. Francony G, Fauvage B, Falcon D, Canet C, Dilou H, Lavagne P, et al: Equimolar doses of mannitol and hypertonic saline in the treatment of increased intracranial pressure. Crit Care Med 36:795-800, 2008

14. Froelich M, Ni Q, Wess C, Ougorets I, Härtl R: Continuous hypertonic saline therapy and the occurrence of complications in neurocritically ill patients. Crit Care Med 37:14331441,2009

15. Gerber LM, Chiu YL, Carney N, Härtl R, Ghajar J: Marked reduction in mortality in patients with severe traumatic brain injury. Clinical article. J Neurosurg 119:1583-1590, 2013

16. Härtl R, Bardt TF, Kiening KL, Sarrafzadeh AS, Schneider GH, Unterberg AW: Mannitol decreases ICP but does not improve brain-tissue pO2 in severely head-injured patients with intracranial hypertension. Acta Neurochir Suppl 70:40-42, 1997
17. Härtl R, Ghajar J, Hochleuthner H, Mauritz W: Hypertonic/ hyperoncotic saline reliably reduces ICP in severely headinjured patients with intracranial hypertension. Acta Neurochir Suppl 70:126-129, 1997

18. Härtl R, Ghajar J, Hochleuthner H, Mauritz W: Treatment of refractory intracranial hypertension in severe traumatic brain injury with repetitive hypertonic/hyperoncotic infusions. Zentralbl Chir 122:181-185, 1997

19. Härtl R, Medary MB, Ruge M, Arfors KE, Ghahremani F, Ghajar J: Hypertonic/hyperoncotic saline attenuates microcirculatory disturbances after traumatic brain injury. J Trauma 42 (5 Suppl):S41-S47, 1997

20. Horn P, Münch E, Vajkoczy P, Herrmann P, Quintel M, Schilling L, et al: Hypertonic saline solution for control of elevated intracranial pressure in patients with exhausted response to mannitol and barbiturates. Neurol Res 21:758-764, 1999

21. Ichai C, Armando G, Orban JC, Berthier F, Rami L, SamatLong C, et al: Sodium lactate versus mannitol in the treatment of intracranial hypertensive episodes in severe traumatic brain-injured patients. Intensive Care Med 35:471-479, 2009

22. Jones PA, Chambers IR, Lo TY, Andrews PJ, Chaudhry W, Clark A, et al: Quantification of secondary CPP insult severity in paediatric head injured patients using a pressure-time index. Acta Neurochir Suppl 95:29-32, 2005

23. Kahraman S, Dutton RP, Hu P, Xiao Y, Aarabi B, Stein DM, et al: Automated measurement of "pressure times time dose" of intracranial hypertension best predicts outcome after severe traumatic brain injury. J Trauma 69:110-118, 2010

24. Kamel H, Navi BB, Nakagawa K, Hemphill JC III, Ko NU: Hypertonic saline versus mannitol for the treatment of elevated intracranial pressure: a meta-analysis of randomized clinical trials. Crit Care Med 39:554-559, 2011

25. Kerwin AJ, Schinco MA, Tepas JJ III, Renfro WH, Vitarbo EA, Muehlberger M: The use of $23.4 \%$ hypertonic saline for the management of elevated intracranial pressure in patients with severe traumatic brain injury: a pilot study. J Trauma 67:277-282, 2009

26. Khanna S, Davis D, Peterson B, Fisher B, Tung H, O'Quigley $\mathrm{J}$, et al: Use of hypertonic saline in the treatment of severe refractory posttraumatic intracranial hypertension in pediatric traumatic brain injury. Crit Care Med 28:1144-1151, 2000

27. Koenig MA, Bryan M, Lewin JL III, Mirski MA, Geocadin RG, Stevens RD: Reversal of transtentorial herniation with hypertonic saline. Neurology 70:1023-1029, 2008

28. Marks JA, Li S, Gong W, Sanati P, Eisenstadt R, Sims C, et al: Similar effects of hypertonic saline and mannitol on the inflammation of the blood-brain barrier microcirculation after brain injury in a mouse model. J Trauma Acute Care Surg 73:351-357, 2012

29. Marmarou A, Anderson RL, Ward JD, Choi SC, Young HF, et al: Impact of ICP instability and hypotension on outcome in patients with severe head trauma. J Neurosurg 75 (Suppl 1s):S59-S66, 1991

30. Marshall LF, Smith RW, Rauscher LA, Shapiro HM: Mannitol dose requirements in brain-injured patients. J Neurosurg 48:169-172, 1978

31. Mendelow AD, Teasdale GM, Russell T, Flood J, Patterson J, Murray GD: Effect of mannitol on cerebral blood flow and cerebral perfusion pressure in human head injury. $\mathbf{J}$ Neurosurg 63:43-48, 1985

32. Mortazavi MM, Romeo AK, Deep A, Griessenauer CJ, Shoja MM, Tubbs RS, et al: Hypertonic saline for treating raised intracranial pressure: literature review with meta-analysis. A review. J Neurosurg 116:210-221, 2012

33. Muizelaar JP, Lutz HA III, Becker DP: Effect of mannitol on ICP and CBF and correlation with pressure autoregulation in severely head-injured patients. J Neurosurg 61:700-706, 1984 
34. Muizelaar JP, Wei EP, Kontos HA, Becker DP: Mannitol causes compensatory cerebral vasoconstriction and vasodilation in response to blood viscosity changes. J Neurosurg 59:822-828, 1983

35. Narayan RK, Kishore PR, Becker DP, Ward JD, Enas GG, Greenberg RP, et al: Intracranial pressure: to monitor or not to monitor? A review of our experience with severe head injury. J Neurosurg 56:650-659, 1982

36. Nath F, Galbraith S: The effect of mannitol on cerebral white matter water content. J Neurosurg 65:41-43, 1986

37. Oddo M, Levine JM, Frangos S, Carrera E, MaloneyWilensky E, Pascual JL, et al: Effect of mannitol and hypertonic saline on cerebral oxygenation in patients with severe traumatic brain injury and refractory intracranial hypertension. J Neurol Neurosurg Psychiatry 80:916-920, 2009

38. Peterson B, Khanna S, Fisher B, Marshall L: Prolonged hypernatremia controls elevated intracranial pressure in headinjured pediatric patients. Crit Care Med 28:1136-1143, 2000

39. Qureshi AI, Suarez JI, Castro A, Bhardwaj A: Use of hypertonic saline/acetate infusion in treatment of cerebral edema in patients with head trauma: experience at a single center. $\mathbf{J}$ Trauma 47:659-665, 1999

40. Rockswold GL, Solid CA, Paredes-Andrade E, Rockswold SB, Jancik JT, Quickel RR: Hypertonic saline and its effect on intracranial pressure, cerebral perfusion pressure, and brain tissue oxygen. Neurosurgery 65:1035-1042, 2009

41. Roquilly A, Mahe PJ, Latte DD, Loutrel O, Champin P, Di Falco C, et al: Continuous controlled-infusion of hypertonic saline solution in traumatic brain-injured patients: a 9-year retrospective study. Crit Care 15:R260, 2011

42. Rosenbaum PR: Optimal matching for observational studies. J Am Stat Assoc 84:1024-1032, 1989

43. Rusnak M, Janciak I, Majdan M, Wilbacher I, Mauritz W: Severe traumatic brain injury in Austria VI: effects of guideline-based management. Wien Klin Wochenschr 119:64-71, 2007

44. Schatzmann C, Heissler HE, König K, Klinge-Xhemajli P, Rickels E, Mühling M, et al: Treatment of elevated intracranial pressure by infusions of $10 \%$ saline in severely head injured patients. Acta Neurochir Suppl 71:31-33, 1998

45. Schwartz ML, Tator CH, Rowed DW, Reid SR, Meguro K, Andrews DF: The University of Toronto head injury treatment study: a prospective, randomized comparison of pentobarbital and mannitol. Can J Neurol Sci 11:434-440, 1984

46. Sheth KN, Stein DM, Aarabi B, Hu P, Kufera JA, Scalea TM, et al: Intracranial pressure dose and outcome in traumatic brain injury. Neurocrit Care 18:26-32, 2013

47. Smith HP, Kelly DL Jr, McWhorter JM, Armstrong D, Johnson R, Transou C, et al: Comparison of mannitol regimens in patients with severe head injury undergoing intracranial monitoring. J Neurosurg 65:820-824, 1986

48. Vialet R, Albanèse J, Thomachot L, Antonini F, Bourgouin
A, Alliez B, et al: Isovolume hypertonic solutes (sodium chloride or mannitol) in the treatment of refractory posttraumatic intracranial hypertension: $2 \mathrm{~mL} / \mathrm{kg} 7.5 \%$ saline is more effective than $2 \mathrm{~mL} / \mathrm{kg} 20 \%$ mannitol. Crit Care Med 31:1683-1687, 2003

49. Vik A, Nag T, Fredriksli OA, Skandsen T, Moen KG, Schirmer-Mikalsen K, et al: Relationship of "dose" of intracranial hypertension to outcome in severe traumatic brain injury. Clinical article. J Neurosurg 109:678-684, 2008

50. Wainwright MS, Lewandowski R: Bioinformatics analysis of mortality associated with elevated intracranial pressure in children. Acta Neurochir Suppl 114:67-73, 2012

51. Ware ML, Nemani VM, Meeker M, Lee C, Morabito DJ, Manley GT: Effects of $23.4 \%$ sodium chloride solution in reducing intracranial pressure in patients with traumatic brain injury: a preliminary study. Neurosurgery 57:727-736, 2005

52. Wells DL, Swanson JM, Wood GC, Magnotti LJ, Boucher BA, Croce MA, et al: The relationship between serum sodium and intracranial pressure when using hypertonic saline to target mild hypernatremia in patients with head trauma. Crit Care 16:R193, 2012

53. Willerson JT, Curry GC, Atkins JM, Parkey R, Horwitz LD: Influence of hypertonic mannitol on ventricular performance and coronary blood flow in patients. Circulation 51:10951100, 1975

54. Wisner DH, Schuster L, Quinn C: Hypertonic saline resuscitation of head injury: effects on cerebral water content. J Trauma 30:75-78, 1990

\section{Author Contributions}

Conception and design: Mangat, Ghajar, Härtl. Acquisition of data: Chiu, Gerber, Härtl. Analysis and interpretation of data: Chiu, Gerber. Drafting the article: Mangat, Ghajar, Härtl. Critically revising the article: all authors. Reviewed submitted version of manuscript: Mangat, Chiu, Gerber, Ghajar, Härtl. Approved the final version of the manuscript on behalf of all authors: Mangat. Statistical analysis: Chiu, Gerber, Alimi. Administrative/technical/material support: Mangat. Study supervision: Ghajar, Härtl.

\section{Supplemental Information}

Previous Presentation

Parts of these findings were presented in poster form at the annual meeting of the Neurocritical Care Society, Denver, Colorado, October 5, 2012.

\section{Correspondence}

Halinder S. Mangat, Department of Neurology, Division of Neurocritical Care, Weill Cornell Medical College, 525 E. 68 St, F-610, New York, NY 10065. email: hsm9001@med.cornell.edu. 